\title{
Using Spiritual Interventions in Psychotherapy: Practices, Successes, Failures, and Ethical Concerns of Mormon Psychotherapists
}

\author{
P. Scott Richards \\ Brigham Young University - Provo, scott_richards@byu.edu \\ Richard W. Potts \\ Brigham Young University - Provo
}

Follow this and additional works at: https://scholarsarchive.byu.edu/facpub

Part of the Student Counseling and Personnel Services Commons

\section{Original Publication Citation}

Richards, P. S. \& Potts, R. (1995). Using spiritual interventions in psychotherapy: Practices, successes, failures and ethical concerns of Mormon psychotherapists. Professional Psychology: Research and Practice, 26, 163-170.

\section{BYU ScholarsArchive Citation}

Richards, P. Scott and Potts, Richard W., "Using Spiritual Interventions in Psychotherapy: Practices, Successes, Failures, and Ethical Concerns of Mormon Psychotherapists" (1995). Faculty Publications. 3863.

https://scholarsarchive.byu.edu/facpub/3863

This Peer-Reviewed Article is brought to you for free and open access by BYU ScholarsArchive. It has been accepted for inclusion in Faculty Publications by an authorized administrator of BYU ScholarsArchive. For more information, please contact ellen_amatangelo@byu.edu. 


\title{
Using Spiritual Interventions in Psychotherapy: Practices, Successes, Failures, and Ethical Concerns of Mormon Psychotherapists
}

\author{
P. Scott Richards and Richard W. Potts \\ Brigham Young University
}

\begin{abstract}
Two hundred and fifteen (out of 300) randomly selected Mormon psychotherapists were surveyed and asked to indicate how frequently they use various spiritual interventions in psychotherapy and to describe successful and unsuccessful spiritual intervention case examples. The therapists indicated that they use a wide variety of spiritual interventions, including praying silently for clients, teaching spiritual concepts, encouraging forgiveness, and using the religious community as a support. Many spiritual interventions were perceived by the therapists as potentially therapeutic. Process guidelines for using spiritual interventions were offered by the therapists, and ethical concerns (e.g., dual relationships, imposing values) were raised. Implications for psychotherapy practice and training are discussed.
\end{abstract}

A broad-based, ecumenical, interdisciplinary effort is underway to develop a spiritual orientation or strategy in psychology and psychotherapy (Bergin, 1980, 1991; Bergin \& Payne, 1991; Jones, 1994; Worthington, 1986). Bergin (1988, 1991) has suggested that such an orientation can make unique contributions to the psychotherapeutic enterprise by providing (a) a spiritual conception of human nature and personality, (b) a moral frame of reference for guiding and evaluating psychotherapy, (c) a body of literature and training opportunities to help all psychotherapists better fulfill their ethical obligation to understand and respect their religious clientele (American Psycho-

P. SCOTT RichaRDS received his PhD in counseling psychology from the University of Minnesota (Minneapolis) in 1988. He is an associate professor in the Department of Educational Psychology at Brigham Young University, where he serves as the director of training for the $\mathrm{PhD}$ program in counseling psychology. He teaches courses in advanced research methodology, theories of counseling supervision, and religious and spiritual issues in psychotherapy. His major research interests are in religious and spiritual issues in mental health and psychotherapy. RICHARD W. POTTS received his MEd in counseling and guidance from Brigham Young University in 1985 . He is currently a doctoral candidate in counseling psychology at Brigham Young University and is completing his predoctoral internship this year at the Utah Valley Regional Medical Center in Provo, Utah. His major research interests are in spirituality and self-esteem and spiritual issues in psychotherapy.

THIS RESEARCH was supported in part by a faculty research grant from the College of Education at Brigham Young University.

WE GRATEFULLY ACKNOWLEDGE helpful suggestions and comments on an earlier draft of this article by Allen E. Bergin, Aaron P. Jackson, Scott Nebeker, I. Reed Payne, Ken Seely, Mack Stephensen, and Logan Zemp. PORTIONS OF THIS ARTICLE were presented at the 102nd Annual Convention of the American Psychological Association in Los Angeles, CA, August 15, 1994.

CORRESPONDENCE CONCERNING THIS ARTICLE should be addressed to P. Scott Richards, 320D MCKB, Department of Educational Psychology, Brigham Young University, Provo, Utah 84602. logical Association [APA], 1992), and (d) a set of spiritual therapeutic techniques and interventions.

Major work remains to be done in developing this spiritual orientation; nevertheless, progress is being made. Efforts have been made to articulate a spiritual view of human nature and personality (Bergin, 1980, 1983, 1988, 1991; Bergin \& Payne, 1991; Gartner, Larson, \& Allen, 1991; Payne, Bergin, Bielema, \& Jenkins, 1991; Worthington, 1989) and to propose moral and spiritual frames of reference for therapy (e.g., Bergin, 1985, 1988; Lovinger, 1984; Spero, 1985; Worthington, 1990). In addition, a substantial body of professional literature now exists in this domain, and formal training opportunities are beginning to be made available (Bergin, 1991; Jones, 1994; Kelly, 1993; Tan, 1993).

A considerable amount of effort has also been made by psychotherapists to develop and implement spiritual interventions in their therapeutic work. For example, Ball and Goodyear (1991) surveyed $174 \mathrm{Christian}$ psychologists and asked them to list any interventions that they had used one or more times that they considered unique to Christian counseling. The most frequently reported interventions were prayer, teaching of theological concepts, and reference to scripture. Spiritual relaxation and imagery techniques, forgiveness, therapist spiritual self-disclosure, and spiritual homework assignments were also occasionally reported.

In a more in-depth process study of religious psychotherapy, Worthington, Dupont, Berry, and Duncan (1988) found that seven Christian psychotherapists also used a wide variety of spiritual interventions in their work. Religious homework assignments, quoting and interpreting scripture, discussion of faith, and prayer were used most frequently by the therapists (in more than $30 \%$ of their sessions). Teaching with scripture, forgiveness of others, and Christian reading were also occasionally used.

It appears that most therapists who use spiritual interventions integrate them with mainstream secular therapeutic approaches (Payne, Bergin, \& Loftus, 1992). For example, Propst, 
Ostrom, Watkins, Dean, and Mashburn (1992) supplemented standard cognitive-behavioral therapy by infusing religious imagery and scriptural reflections into their treatment approach. Worthington (1990) said he integrates Christian values and interventions such as prayer, discussion of scripture, and forgiveness with secular approaches such as cognitive-behavioral, structural, and strategic marital therapy. Efforts to integrate spiritual concepts and interventions with psychodynamic, existential-humanistic, and health psychology approaches have also been made (Payne et al., 1992).

Although considerable work has been done, we still do not have a very clear idea of how widespread or frequent the use of various spiritual interventions is by therapists from different religious traditions or geographic regions. In addition, although a few outcome studies have shown that including a spiritual component in the treatment package may enhance the effectiveness of secular approaches for religious clientele (e.g., Pecheur \& Edwards, 1984; Propst, 1980; Propst et al., 1992), we still know very little about the types of positive or negative outcomes that may result from spiritual interventions.

We also know very little about therapists' attitudes regarding the ethical appropriateness of using spiritual interventions in their professional work. The implementation of spiritual interventions in psychotherapy raises potentially difficult questions regarding the limits of professional role boundaries. Tjeltveit (1986) argued that psychotherapists "need to openly distinguish their tasks from those of ethicists, religious professionals, and political theorists" (p. 527). Do psychotherapists believe they can use spiritual interventions in their therapeutic work without stepping outside the boundaries of their professional role?

Thus, although significant efforts have been made to implement a spiritual strategy into mainstream psychotherapy practice, many questions about how we can do this effectively and ethically remain unanswered. In an effort to gain more insight into these questions, we surveyed a national sample of Mormon psychotherapists and investigated the following four research questions:

1. How frequently do Mormon psychotherapists use various spiritual interventions in their professional work?

2. What spiritual interventions are most often perceived by Mormon psychotherapists as effective or ineffective?

3. What types of positive and negative outcomes do Mormon psychotherapists perceive are associated with spiritual interventions?

4. What are Mormon psychotherapists' attitudes regarding the ethical appropriateness of using various spiritual interventions in their professional work?

Previous research on spiritual interventions has been done with therapists from a variety of Christian faiths (e.g., Pentecostal, Presbyterian, Baptist); however, Mormon therapists have not been studied. The Mormon church is distinctive in its doctrine, ecclesiastical structure, and cultural tradition, and is rapidly growing and spreading throughout the world (Stark, 1984). We believed, therefore, that a study of the beliefs and practices of Mormon psychotherapists was justified and would make a contribution to the literature in this domain. Because so little is currently known about the effects of spiritual inter- ventions, we also believed an exploration of therapists' perceptions regarding the outcomes of spiritual interventions would be of interest and would lay the groundwork for more rigorously designed therapy outcome studies.

\section{Method}

\section{Procedure}

In September 1992, we randomly selected 300 psychotherapists in the United States and Canada from the current membership directory of the Association of Mormon Counselors and Psychotherapists (AMCAP). AMCAP is a professional organization of approximately 600 counselors and psychotherapists whose common bond is membership in and / or adherence to the principles and standards of The Church of Jesus Christ of Latter-Day Saints (Mormons).

In late October 1992, participants were mailed a survey packet that included a cover letter, an informed consent document, and a copy of the survey. In early January 1993, a follow-up letter and second copy of the survey was sent to therapists who had not yet responded to the survey. In early March 1993, a postcard was sent to therapists who had not yet responded to the survey. Approximately 130 participants returned the survey after the first mailing, 70 more after the second mailing, and 15 more after the postcard was sent for a total of 215 responses (total return rate of $72 \%$ ).

\section{Participants}

There were $122(60 \%)$ male and $83(40 \%)$ female therapists. The average age of the therapists was 48 years ( $S D=9.9$ years). One hundred and thirty-two (70\%) of the therapists were licensed. The average caseload of the therapists was 20.6 clients per week $(S D=15.9)$. On the average, $63 \%(S D=34.2 \%)$ of the therapists' clients each week were Mormons. The majority of therapists were from the western United States ( 77 from Utah, 31 from California, 27 from Idaho); however, therapists from other regions in the United States and from Canada were also represented. There were 40 psychologists, 64 clinical social workers, 37 marriage and family therapists, 35 counselors, 4 psychiatrists, 2 school psychologists, and 16 other professionals (e.g., chaplains, family physicians). Seventy-four therapists had doctoral degrees, and 129 had master's degrees.

Sixty-eight of the therapists worked primarily in private practice, 38 for Latter-Day Saints (LDS) Social Services, 23 in community mental health centers, 19 in hospitals, 18 in schools, 12 in university counseling centers, 10 for government social services, 8 in university academic departments, and 5 in other settings (e.g., military and industry). Ninetyfive of the therapists indicated they were eclectic in their therapy orientation, 54 were cognitive-behavioral, 12 were psychodynamic, 8 were systemic, and 14 used some other orientation (e.g., client-centered). The therapists as a group provided services to a wide variety of clients including children, adolescents, and adults. As a group the therapists also provided a wide variety of professional services including marriage and family therapy, personal-emotional therapy, career-vocational counseling, drug and alcohol abuse counseling, and pastoral counseling.

\section{Survey Description}

The first page of the survey asked respondents to provide background and demographic information. On the second and third pages of the survey, nine "in-session" and nine "out-of-session" spiritual interventions were listed (see Table 1) and defined, and the respondents were asked to indicate on a 6-point Likert scale $(0=$ Never, $1=$ Rarely, $2=$ Occasionally, 3 = Often, $4=$ Very Often, $5=$ Always) how frequently 
Table 1

Definitions, Usage Rates, and Critical Incident Sample Sizes Reported by Therapists for Various Spiritual Interventions

\begin{tabular}{|c|c|c|c|c|c|}
\hline \multirow[b]{2}{*}{ Spiritual intervention } & \multirow[b]{2}{*}{ Definition" } & \multicolumn{2}{|c|}{ Usage rate $^{b}$} & \multicolumn{2}{|c|}{$\begin{array}{c}\text { Critical incident } \\
\text { sample size }\end{array}$} \\
\hline & & $M$ & $S D$ & Effective & Ineffective \\
\hline \multicolumn{6}{|l|}{ In-session intervention } \\
\hline Therapist prayer & Therapist silent prayer & 2.97 & 1.51 & 2 & 1 \\
\hline Teaching spiritual concepts & $\begin{array}{l}\text { Teaching or instructing clients about theological issues } \\
\text { and spiritual concepts }\end{array}$ & 2.47 & 1.10 & 30 & 14 \\
\hline Reference to scripture & $\begin{array}{l}\text { Direct quotation or citation of scripture to establish a } \\
\text { point }\end{array}$ & 1.85 & 1.09 & 33 & 9 \\
\hline Spiritual self-disclosure & $\begin{array}{l}\text { Therapist self-discloses or models spiritual experiences or } \\
\text { behaviors in an attempt to influence the client }\end{array}$ & 1.80 & 1.09 & 11 & 4 \\
\hline Spiritual confrontation & $\begin{array}{l}\text { Interventions that confront a client concerning religious/ } \\
\text { spiritual beliefs and values }\end{array}$ & 1.77 & 1.11 & 1 & 5 \\
\hline Spiritual assessment & $\begin{array}{l}\text { Employing the initial counseling session as a way to } \\
\text { assess the client's religious and spiritual status }\end{array}$ & 1.66 & 1.48 & 2 & 1 \\
\hline $\begin{array}{l}\text { Religious relaxation or } \\
\text { imagery }\end{array}$ & $\begin{array}{l}\text { The use of guided imagery, meditation, or relaxation } \\
\text { with direct reference to spiritual concepts; often with } \\
\text { visualization of God or Christ }\end{array}$ & 1.09 & 1.20 & 14 & 1 \\
\hline Therapist and client prayer & Vocal in-session prayer with client & 0.72 & 1.00 & 9 & 2 \\
\hline Blessing by therapist & $\begin{array}{l}\text { Use of priesthood blessings (laying on of hands) in- } \\
\text { session to help client cope or work through impasses }\end{array}$ & 0.43 & 0.75 & 10 & 2 \\
\hline \multicolumn{6}{|l|}{ Out-of-session intervention } \\
\hline Encouraging forgiveness & $\begin{array}{l}\text { Discussing the concept of forgiveness with client; } \\
\text { encouraging client to forgive parents or others }\end{array}$ & 2.88 & 1.12 & 12 & 7 \\
\hline Use religious community & $\begin{array}{l}\text { Employing the client's religious community as an extra- } \\
\text { therapy resource }\end{array}$ & 2.64 & 1.13 & 11 & 11 \\
\hline Client prayer & Encouraging client private prayers & 2.28 & 1.26 & 12 & 7 \\
\hline Encouraging client confession & $\begin{array}{l}\text { Encouraging the client to confess violations of moral } \\
\text { code to appropriate persons and to seek repentance }\end{array}$ & 2.00 & 1.29 & 5 & 3 \\
\hline Referral for blessing & $\begin{array}{l}\text { Encouraging client to request priesthood blessing from } \\
\text { home teacher or religious leader to help client work } \\
\text { through impasses }\end{array}$ & 1.84 & 1.31 & 6 & 2 \\
\hline Religious journaling & $\begin{array}{l}\text { Asking client to keep journal concerning spiritual } \\
\text { struggles, insights, and experiences }\end{array}$ & 1.76 & 1.33 & 2 & 1 \\
\hline Spiritual meditation & $\begin{array}{l}\text { Encouraging meditation about spiritual matters to } \\
\text { promote client spiritual growth }\end{array}$ & 1.67 & 1.22 & 2 & 0 \\
\hline Religious bibliotherapy & Giving clients religious and spiritual literature to read & 1.62 & 1.27 & 14 & 4 \\
\hline Scripture memorization & $\begin{array}{l}\text { Interventions specifically using client memorization of } \\
\text { scriptures to affect change }\end{array}$ & 0.55 & 0.85 & 0 & 0 \\
\hline
\end{tabular}

- Definitions were adapted from Ball and Goodyear (1991). ${ }^{b}$ Response scale for usage rates was: $0=$ never; $1=$ rarely; $2=$ occasionally; $3=$ often; $4=$ very often; $5=$ always. $\quad$ "Critical incident sample sizes refer to the number of therapists who mentioned this intervention when describing an effective or ineffective spiritual intervention in their critical incident case reports.

they had used the techniques or interventions during the past year in their professional therapeutic role. At the bottom of page 3, we also asked respondents to indicate (Yes or No) whether they believed there are any religious or spiritual techniques that therapists should not use in their professional role and, if so, to state which ones.

On page 4, the instructions read, "We are interested in finding out when you feel religious or spiritual techniques have been effective or ineffective with your clients. Please recall, if you can, an occasion where you felt a religious/spiritual technique was particularly effective in helping your client grow or change." Therapists were then asked to describe the case without disclosing details that would make it possible to establish the client's identity. The instructions on page 5 were identical, except respondents were asked to recall and describe an occasion when they felt a religious or spiritual technique was clearly ineffective in helping a client change.

\section{Data Analysis}

Means and standard deviations were computed to describe how often the AMCAP members used the various spiritual interventions. A li- censed counseling psychologist and two graduate students in counseling psychology served as judges and used qualitative data analysis procedures to analyze the critical incident case reports. Qualitative data analysis is a discovery-oriented, intuitive process in which objective, quantitative methods are set aside in favor of a more subjective, creative approach to making sense of written data (e.g., interview transcripts, field notes, case reports, etc.; Taylor \& Bogdan, 1984).

In the present study, each judge independently studied the therapist critical incident case reports and carefully searched for possible themes or categories in the information. After identifying possible themes in the data and documenting which therapist responses fit into the various themes, the judges then met and compared their descriptions of the themes and the supporting evidence. The judges resolved discrepancies in opinion about the themes by carefully reexamining the critical incident case reports and through discussion concerning the nature of the themes and the supporting evidence for each theme. The major criteria used by the judges for deciding whether they agreed a theme existed was whether there were at least four or five therapist statements present in 
the case reports that the judges agreed clearly communicated the message of that theme.'

\section{Results}

\section{Usage Rates}

Table 1 reports the usage rates of the various spiritual interventions by all psychotherapists who responded to the survey. For example, "therapist ( silent) prayer" was the most frequently used in-session spiritual intervention. The mean endorsement rate across all therapists for therapist (silent) prayer was $2.97(S D=1.51)$, which indicates that, on the average, the Mormon psychotherapists often offer silent in-session prayers on behalf of clients. The least frequently used in-session spiritual intervention was "blessing (laying on of hands) by the therapist" $(M=0.43)$.

\section{Spiritual Interventions Therapists Should Not Use}

Seventy-three percent of the therapists said they believe there are some spiritual interventions therapists should not use in their professional role. The spiritual interventions mentioned most frequently by the therapists as inappropriate for therapists to use were priesthood blessings (laying on of hands) by the therapist (mentioned by 79 therapists), encouraging clients to confess ( 34 therapists), client and therapist in-session prayer (33), and spiritual self-disclosure or modeling (22).

\section{Qualitative Results}

One-hundred and seventeen therapists ( $53 \%$ ) described in a critical incident case report at least one occasion when they had used a spiritual intervention and had perceived that it had been particularly effective in helping their client grow or change. Seventy-three therapists (34\%) described at least one occasion when they had used a spiritual intervention and perceived that it was particularly ineffective in helping their client grow or change. Some therapists mentioned several effective or ineffective attempts to use spiritual interventions.

Table 1 reports which spiritual interventions were most frequently perceived in the critical incident case reports as effective or ineffective. For example, 33 therapists reported a case in which they had made "reference to scripture" during the session and perceived that this intervention had been particularly effective in helping their client grow or change, but 9 therapists described a case in which they had made reference to scripture and perceived this intervention as ineffective.

According to the therapists' critical incident case reports, spiritual interventions were used effectively with a variety of clients and presenting concerns (e.g., depression and grief, marital conflict, childhood sexual abuse, low self-esteem, suicidal ideation, eating disorders, and sexual concerns). The therapists also reported that the spiritual interventions resulted in a wide variety of positive outcomes for their clients; for example, the interventions strengthened their clients' self-esteem and feelings of worth $(N=38)$; promoted client peace, acceptance, and love of self and others ( $N=28$ ); improved client's relationships ( $N$ $=28)$; increased client's spirituality $(N=18)$; helped clients feel empowered in terms of autonomy, control, and boundaries $(N=14)$; instilled clients with hope, courage, and motivation $(N=14)$; promoted client cognitive insight and restructuring $(N=10)$; facilitated emotional catharsis and working through $(N=12)$; and provided general symptom relief $(N=48)$.

According to the therapists, spiritual interventions have also been ineffective with a variety of clients and presenting concerns (e.g., marital conflict, childhood sexual abuse, depression, personality disorders, sexual concerns, low self-esteem, psychosis, severe anxiety and agoraphobia, drug or alcohol abuse). The therapists also reported that their ineffective spiritual interventions resulted in a number of potentially negative outcomes for their clients, such as anger at the therapist, the religious leader, or both $(N=15)$; no change $(N=13)$; the client felt shamed, hurt, or confused $(N=12)$; the client exhibited denial and resistance $(N=10)$; the client rejected the intervention $(N=9)$; the client terminated prematurely $(N=7)$; and the client felt coerced and manipulated $(N=6)$.

\section{Process Themes or Guidelines}

Eight major process themes or guidelines were identified in the qualitative data and are listed here along with one or two illustrative quotes from therapists.

1. Use spiritual interventions only when prompted and guided by the spirit of God to do so. One therapist said that she used a particular spiritual intervention "as I felt prompted by the spirit." Another therapist said, "Religious techniques should be . . . used only under the direction of the spirit and requires a deep personal commitment and spiritual preparation from the therapist."

2. Establish a relationship of trust with the client before using spiritual interventions. One therapist, who used several spiritual interventions with a Mormon male client who was having marital problems, said that he used the spiritual interventions "after meeting with him five or six times and establishing a definite relationship and trust . . . I believe it is beneficial to utilize certain spiritual interventions after you have established rapport and trust."

3. Obtain the client's permission before using spiritual interventions to make sure the client is comfortable with using them. One therapist said, "Employment of spiritual interventions and techniques should be the result of heavy client participation in deciding when, how, and to what extent those interventions are to be utilized." Another therapist said, "I believe that spiritual and religious interventions . . . should be used with full client consent, as part of the client-therapist contract."

4. Assess the client's religious beliefs and doctrinal understanding before using spiritual interventions. One therapist, who was working with a 30 -year-old, depressed, Mormon female client said that she "suggested personal prayer for relief. . . . The woman confessed non-belief [in God] or at best, confusion regarding religion generally and Mormonism specifically. . . . Personal prayer ought not to be recommended unless reli-

\footnotetext{
${ }^{1}$ A more detailed presentation of the data analysis and results reported here is available on request from P. Scott Richards.
} 
gious experiences of the individual are assessed. I clearly erred in assuming religiosity upon appearances alone."

5. Work within the client's value framework and level of spirituality. One therapist said, "I always work within the framework of the client's value system." Another therapist said, "adapting the spiritual intervention to the client rather than using it as a stock item for all is important."

6. Use spiritual interventions carefully and sparingly. One therapist said, "Spiritual interventions can be very powerful but should be used with great care and discretion." Another therapist said, "Religious techniques should be used rarely and cautiously."

7. Spiritual interventions may be less effective with severely disturbed clients. One therapist, in relating an ineffective attempt to use a spiritual intervention, said, "the technique was marginally effective mostly I believe due to the client's poor functional state. She was hospitalized two times in the past year and was on psychotropics."

8. Use caution in using spiritual interventions if religion seems to be part of the client's problem. One therapist said, "Spiritual interventions are difficult when the client was abused as a child and blames God for not protecting them. In such cases deity becomes enmeshed in the client's adverse feelings and becomes part of the problem."

\section{Ethical Concerns}

Five major ethical concerns or dangers regarding the use of spiritual interventions that were mentioned in the qualitative data are listed below along with illustrative quotes from therapists.

1. The danger of engaging in dual relationships, or of usurping religious authority. One therapist said, "I consider assessing spiritual status and in-session priesthood blessings to be unethical . . . a dual-relationship . . . I am a psychologist and I see the role of a therapist as separate to that of a religious leader." Another therapist said, "I believe we must be careful not to confuse our role and the priesthood leader's role lest we supplant them inappropriately through our role authority in therapy."

2. The danger of engaging in priestcraft (i.e., getting paid for spiritual service). One therapist said, "I have always feared slipping into priestcraft. I give blessings (laying on of hands) to family and friends-for no money. I suggest clients seek blessings from family members . . . or priesthood leaders." Another therapist said, "A priesthood blessing should not come from someone who is being paid."

3. The danger of trivializing the numinous or the sacred. One therapist said,

my understanding of the divine and my experience both persuade me to avoid consciously-planned use of explicit religious or spiritual matters in my work in therapy. I even cringe of thinking of these as "techniques," just as I am troubled by having such matters as "love" and "faith" spoken of as "techniques." . . . My primary concern is not our corrupting our therapy. . . . My concern is our trivializing the numinous, our losing our awe of the divine, our forgetting the fear of the LORD.

4. The danger of imposing our religious values on clients.
One therapist said that she is careful "never to push my religious orientation or beliefs." Another therapist said,

I have strong feelings about using religious techniques in therapy and about therapists, who use them to "make sure" their patients make the right choices. I don't believe we can walk with our patients in their unique pain if we, in essence, do the work of their religious leader instead of our work.

5. The danger of using spiritual interventions inappropriately in certain work settings. One therapist said,

I personally believe that the use of spiritual and religious techniques in therapy depends on the nature of the work place. I work for the state . . . and am not at liberty to use spiritual or religious techniques I would like.

\section{Spiritual Interventions Belong in Therapeutic Practice}

Despite the ethical concerns raised and the belief expressed by some therapists that spiritual interventions have no place in professional therapeutic practice, a majority of therapists expressed a belief that spiritual interventions, if used appropriately, can significantly enhance the efficacy of psychotherapy. One therapist said, "spiritual interventions are very critical . . . for maximum recovery for most Mormon and non-Mormon clients in my experience." Another said,

many non-Mormon therapists are also recognizing the importance of addressing the spiritual part of our being with their clients. I think it is becoming a more common practice and more accepted as many see it as essential in the process of healing.

\section{Discussion}

Our finding that many Mormon therapists use a wide variety of spiritual interventions in their professional therapeutic work is consistent with other recent studies that have shown that therapists of other Christian denominations also use a variety of spiritual interventions (Ball \& Goodyear, 1991; Worthington et al., 1988). Interestingly, many of the spiritual interventions used most often by the Mormon therapists (e.g., therapist silent prayer, encouragement of clients to forgive others, use of the religious community) were similar to those used most frequently by other Christian therapists (Ball \& Goodyear, 1991; Worthington et al., 1988).

Our finding that the mean usage rates for the spiritual interventions were quite low (ranging from 0.43 to 2.97 on a 6-point scale) indicates, however, that most of the spiritual interventions were used rather infrequently by the Mormon therapists. Consistent with previous research (Payne et al., 1992), therefore, it appears that most of the therapists in our study use spiritual interventions sparingly and as part of an integrative approach that encompasses mainstream secular perspectives and interventions. More research is needed to determine how widespread and frequent the use of various spiritual interventions is by therapists from other religious denominations, and by therapists who claim no religious affiliation or belief.

Our findings also revealed that there was considerable variation in how often the Mormon therapists use specific spiritual interventions. The Mormon therapists we surveyed more often 
used less religiously explicit spiritual interventions such as praying silently for their clients and teaching spiritual concepts in comparison with more explicit interventions such as giving their clients priesthood blessings and praying vocally with their clients. On the average, the Mormon therapists also more often encouraged out-of-session spiritual activities rather than using spiritual interventions explicitly during therapy sessions. Why do the Mormon therapists tend to more frequently use less religiously explicit interventions? Perhaps they believe there is less risk of confusing professional and religious role boundaries when less explicit interventions are used. Perhaps they believe they are less likely to offend clients, or perhaps they simply believe less explicit interventions are more effective. Further research is needed to investigate this question.

It was also of interest that, although there was a fairly strong trend for more frequently used interventions to be mentioned more often in the critical incident reports, there were several exceptions to this (e.g., therapist prayer was used more frequently than any other intervention but was mentioned only three times in the critical incident reports). This raises the possibility that some frequently used spiritual interventions are not particularly effective or, at least, their effects are not readily observed by therapists. Also, some rarely used interventions may be very therapeutic. Clearly, there is a need for more investigation into the various individual spiritual interventions so that we can gain more insight into why and when they are being used and how often they are proving effective.

The qualitative finding that a variety of spiritual interventions, according to the therapists, have resulted in positive, sometimes powerful therapeutic outcomes for clients with a variety of presenting concerns was of much interest. Bergin (1988, 1991 ) has expressed the belief that spiritual influences and interventions can give people added power to heal and change. Although our exploratory study has not empirically proven that spiritual interventions can cause therapeutic change, the case examples provided by the therapists suggest this is a possibility and give added incentive for further empirical study of such interventions. As stated by Bergin (1983), "Examining the mechanisms of change in these situations and not letting prejudices against spiritual language prevent researchers from perceiving potentially beneficial factors could improve therapeutic knowledge" (p. 178).

The qualitative finding that many of the same spiritual interventions therapists reported were effective with some clients were also ineffective on other occasions was of interest but should not be surprising. It is well known that the effectiveness of an intervention does not depend on the technique alone (Bergin \& Garfield, 1994) but also depends on a host of other influences such as client variables (e.g., severity of pathology), counselor variables (e.g., trustworthiness), and process variables (e.g., timing of the intervention). The clinical guidelines offered in this study by the Mormon therapists provided some insight into client, counselor, and process variables that could influence the effectiveness of spiritual interventions and are deserving of empirical study.

The qualitative finding that spiritual interventions can sometimes, according to the Mormon therapists, result in negative outcomes for clients is of serious concern. Although negative outcomes are a possibility when using any therapeutic approach (Bergin \& Garfield, 1994), this finding nevertheless emphasizes the need for more outcome research on spiritual interventions. When new therapeutic orientations and interventions are being developed and implemented, therapists have an added responsibility to monitor and evaluate the efficacy of their work. This has not always been done in the field of psychotherapy (Bergin \& Garfield, 1994), but if a spiritual orientation in psychotherapy is to take its place alongside other enduring therapeutic approaches, we believe it is crucial for therapists who use spiritual interventions to document the efficacy of their work.

The qualitative finding that some therapists believe there are real ethical dangers in using spiritual interventions is a concern others have also raised (e.g., Tjeltveit, 1986; Younggren, 1993) and deserves careful consideration. The possible ethical dangers associated with the use of spiritual interventions raises questions regarding standards of training and practice in this domain of psychotherapy. Should therapists who wish to incorporate a spiritual strategy in their therapeutic work be required to take certain coursework (e.g., courses on religion, theology, the psychology of religion, and religious and spiritual issues in psychotherapy)? Should supervised practicums and clerkships where the therapist works with religiously or spiritually oriented clients and supervisors be required? Does the use of certain spiritual interventions violate professional role boundaries? Do we need more specific standards of practice or a code of ethics to guide our therapeutic work in this domain?

$\operatorname{Tan}$ (1993) believes that training and supervision in religious and spiritual issues is necessary for therapists, and he has pointed out that the current APA (APA, 1992) ethical guidelines acknowledge the need for such training. We agree with him, and believe that a crucial task for the immediate future is for professionals with an interest in this domain to define and implement such training standards and opportunities.

The question of whether more explicit standards of practice or ethical guidelines are needed for those using spiritual interventions is a more difficult one. In our study, there seemed to be widespread agreement among the Mormon therapists that engaging in dual relationships (professional and religious), usurping or trivializing religious authority and tradition, and imposing religious values on clients all need to be avoided. However, there seemed to be a considerable lack of agreement about how to implement these beliefs during the therapeutic hour. What type of information should be shared as part of informed consent procedures, what spiritual interventions should be avoided, and who should initiate consideration of spiritual concerns and interventions during the therapy hour were all issues about which the Mormon therapists seemed to have divergent opinions.

We believe that more explicit ethical guidelines and standards of practice are needed in this domain. We believe that therapists who may use spiritual interventions in their professional work need to inform clients of this possibility during informed consent procedures. Spiritual interventions that may be used should be briefly mentioned, and therapists should inform clients that such interventions will not be used without their consent. Therapists should also remind clients that they have no religious or ecclesiastical authority over the client and that they 
cannot speak for or act on behalf of the church or its leaders. Therapists may also wish to briefly describe some of their fundamental spiritual beliefs and assumptions that are relevant to their therapeutic work (e.g., the belief in a supreme being, the belief that spiritual influences exist and can give people added power to change, the belief that human beings have certain spiritual needs ).

We also believe that extreme caution is warranted in using spiritual interventions when working with clients who do not share the therapist's religious beliefs. Therapists and clients who share a common religious worldview will usually find it easier and safer to work on religious and spiritual issues in therapy because misunderstandings and doctrinal disagreements are less likely. A case example from our critical incident data illustrates this point. One therapist reported that, while working with a Jewish client, he made a reference to Jesus Christ while discussing a spiritual concept. The client was offended by the therapist's religious insensitivity, and a rift was created in the therapeutic relationship. Mistakes such as this are less likely when therapists and clients are of the same faith. However, even when the client belongs to the same religion as the therapist, major differences in belief can exist, and so therapists should not make assumptions about the religious beliefs and values of the client. In respect for individual differences, therapists should seek to understand each client's unique religious understandings.

Because of the ethical imperative psychotherapists have to avoid dual relationships (APA, 1992), we believe therapists should not provide psychotherapy to members who belong to the same congregation as them or to members for whom they have ecclesiastical responsibility. We also believe therapists should avoid using spiritual interventions that might blur the boundaries between professional and religious roles. For example, within the Mormon faith, which has a lay clergy, we believe that giving a client a priesthood blessing (laying on of hands) during a therapy session is problematic because this increases the likelihood that the client will misperceive or be confused about the therapist's role. If the client is paying for the session, it also poses a religious dilemma because in the Mormon faith getting paid for giving a priesthood blessing is viewed as an unrighteous use of priesthood authority.

The role distinctions between religious leaders and professional therapists may vary somewhat from one religion to another, and so spiritual interventions that confuse boundaries and increase the risk of dual relationships in one denomination may not be problematic in another. Perhaps some standards of practice that are ecumenical can be agreed upon, but some may also need to be denominationally specific. We believe, therefore, that professionals within each religious faith, perhaps in consultation with religious authorities of their faith, should be involved in the development of ethical guidelines and standards of practice that are appropriate for their particular faith. We believe there is clearly a need for further discussion and debate about ethical guidelines and standards of practice for therapists who wish to use spiritual interventions. Hopefully such discussion will help clarify some of the uncertainty and disagreement that currently seems to exist in this domain.

\section{Limitations of the Study}

A couple of limitations of this study should be kept in mind. First, although we randomly sampled therapists who belong to AMCAP, not all Mormon therapists are members of AMCAP. One of AMCAP's purposes is to promote professional practices that are in harmony with moral and spiritual principles, and so therapists who belong to AMCAP may be more interested in spiritual interventions than other Mormon therapists. Thus, we cannot safely generalize to all Mormon therapists or, of course, to therapists of other religious faiths.

Second, as with all exploratory survey studies, the data were obtained by self-report and are only descriptive in nature. The spiritual intervention usage rates reported by the therapists may not necessarily accurately reflect actual usage rates. All of the critical incident data regarding the outcomes of various spiritual interventions are based on therapists' perceptions and may not accurately reflect the actual therapeutic outcomes that occurred. Rigorous experimental designs that include multifaceted assessments of outcome (e.g., from the perspective of therapists, clients, and significant others) are needed before firm conclusions about the efficacy of spiritual interventions will be possible.

\section{Conclusion}

Despite its limitations, our study has provided considerable insight into the practices and beliefs of a sample of psychotherapists who are currently using spiritual interventions in their professional work. It has also highlighted the need for more therapy outcome research and for the development of clearer training and ethical standards in this domain.

Some professionals may believe that the ethical dangers associated with implementing a spiritual orientation in psychotherapy are sufficiently grave as to justify a complete exclusion of spiritual perspectives and interventions from professional psychotherapy practice. We believe that this is an extreme and un. warranted position. Certainly ethical dangers do exist, but the therapists in our study, and others contributing to a spiritual strategy (e.g., Bergin, 1988, 1991; Bergin \& Payne, 1991; Tjeltveit, 1986; Younggren, 1993), appear sensitive and willing to address these issues.

We believe that those who would exclude all spiritual perspectives and interventions from psychotherapy are in danger themselves of violating APA's ethical principles regarding respect for human diversity (APA, 1992). We believe, for example, that such therapists are less likely to (a) fully understand and empathize with their religious clients, (b) contextualize their interventions so that they are in harmony with the client's religious belief system, (c) competently use religious and spiritual resources in the client's life, and (d) recognize cultural blind spots that cause them to unknowingly show disrespect or a lack of sensitivity to their client's religious values (Worthington, 1986).

The mental health professions have had a long history of bias and insensitivity to those with religious worldviews, and this needs to end (Bergin, 1980, 1983, 1991; Jones, 1994; Strommen, 1984). It is our hope that researchers and thera- 
pists representing diverse professional, theoretical, cultural, and religious perspectives will contribute to the development of a spiritual orientation in psychology and psychotherapy. We believe this orientation could eventually help enhance all psychotherapists' multicultural sensitivity and therapeutic effectiveness with the large majority of clients who approach life from a religious or spiritual perspective (Bergin, 1980, 1991; Jones, 1994).

\section{References}

American Psychological Association. (1992). Ethical principles of psychologists and code of conduct. American Psychologist, 47, 15971611.

Ball, R. A., \& Goodyear, R. K. (1991). Self-reported professional practices of Christian psychologists. Journal of Psychology and Christianity, 10, 144-153.

Bergin, A. E. (1980). Psychotherapy and religious values. Journal of Consulting and Clinical Psychology, 48, 95-105.

Bergin, A. E. (1983). Religiosity and mental health: A critical reevaluation and meta-analysis. Professional Psychology: Research and Practice, 14, 170-184.

Bergin, A. E. (1985). Proposed values for guiding and evaluating counseling and psychotherapy. Counseling and Values, 29, 99-116.

Bergin, A. E. (1988). Three contributions of a spiritual perspective to psychotherapy and behavior change. Counseling and Values, 33, 21-31.

Bergin, A. E. (1991). Values and religious issues in psychotherapy and mental health. American Psychologist, 46, 394-403.

Bergin, A. E., \& Garfield, S. L. (Eds.). (1994). Handbook of psychotherapy and behavior change (4th ed.). New York: Wiley.

Bergin, A. E., \& Payne, 1. R. (1991). Proposed agenda for a spiritual strategy in personality and psychotherapy. Journal of Psychology and Christianity, 10, 197-210.

Gartner, J., Larson, D. B., \& Allen, G. D. (1991). Religious commitment and mental health: A review of the empirical literature. Journal of Psychology and Theology, 19, 6-25.

Jones, S. L. (1994). A constructive relationship for religion with the science and profession of psychology. American Psychologist, 49. 184-199.

Kelly, E. W. (1993, March). The status of religious and spiritual issues in counselor education. Paper presented at the annual convention of the American Counseling Association, Atlanta, GA.

Lovinger, R. J. (1984). Working with religious issues in therapy. New York: Jason Aronson.

Payne, I. R., Bergin, A. E., Bielema, K. A., \& Jenkins, P. H. (1991). Review of religion and mental health: Prevention and the enhance- ment of psychosocial functioning. Prevention in Human Services, 9 , $11-40$.

Payne, I. R., Bergin, A. E., \& Loftus, P. E. (1992). A review of attempts to integrate spiritual and standard psychotherapy techniques. Journal of Psychotherapy Integration, 2, 171-192.

Pecheur, E., \& Edwards, K. J. (1984). A comparison of secular and religious versions of cognitive therapy with depressed Christian college students. Journal of Psychology and Theology, 12, 45-54.

Propst, L. R. (1980). The comparative efficacy of religious and nonreligious imagery for the treatment of mild depression in religious individuals. Cognitive Therapy and Research, 4, 167-178.

Propst, L. R., Ostrom, R., Watkins, P., Dean, T., \& Mashburn, D. (1992). Comparative efficacy of religious and non-religious cognitive-behavioral therapy for the treatment of clinical depression in religious individuals. Journal of Consulting and Clinical Psychology, 60, 94-103.

Spero, M. H. (Ed.). (1985). Psychotherapy of the religious patient. Springfield, IL: Charles C Thomas.

Stark, R. (1984). The rise of a new world faith. Review of Religious Research, 26, 18-27.

Strommen, M. P. (1984). Psychology's blind spot: A religious faith. Counseling and Values, 28, 150-161.

Tan, S. Y. (1993, January). Training in professional psychology: Diversity includes religion. Paper presented at the National Council of Schools of Professional Psychology (NCSPP) Midwinter Conference on Clinical Training in Professional Psychology, La Jolla, CA.

Taylor, S. J., \& Bogdan, R. (1984). Introduction to qualitative research methods (2nd ed.). New York: Wiley.

Tjeltveit, A. C. (1986). The ethics of value conversion in psychotherapy: Appropriate and inappropriate therapist influence on client values. Clinical Psychology Review, 6, 515-537.

Worthington, E. L., Jr. (1986). Religious counseling: A review of published empirical research. Journal of Counseling and Development, $64,42 I-431$.

Worthington, E. L., Jr. (1989). Religious faith across the life span: Implications for counseling and research. The Counseling Psychologist, 17, 555-612.

Worthington, E. L., Jr. (1990). Marriage counseling: A Christian approach to counseling couples. Counseling and Values, 35, 3-15.

Worthington, E. L., Jr., Dupont, P. D., Berry, J. T., \& Duncan, L. A. (1988). Christian therapists' and clients' perceptions of religious psychotherapy in private and agency settings. Journal of Psychology and Theology, 16, 282-293.

Younggren, J. N. ( 1993). Ethical issues in religious psychotherapy. Register Report, 19, 1, 7-8.

Received February 18, 1994

Revision received August 15, 1994 Accepted October 6, 1994 